\title{
Pars plana vitrectomy for posterior surface calcification in a silicone intraocular lens in asteroid hyalosis - a report of mistaken identity?
}

This article was published in the following Dove Press journal:

Clinical Ophthalmology

I 3 November 2014

Number of times this article has been viewed

\author{
Paul G Rainsbury' \\ Jonathan Lochhead ${ }^{2}$ \\ 'Eye Unit, Queen Alexandra Hospital, \\ Cosham, Portsmouth, Hants, UK; ${ }^{2}$ Eye \\ Unit, St Mary's Hospital, Newport, Isle \\ of Wight, UK
}

\section{Dear editor}

Mehta et al recently reported removal of dystrophic calcification on the posterior surface of a silicone intraocular lens (IOL) in a patient with asteroid hyalosis. ${ }^{1}$ In this case the authors used pars plana vitrectomy (PPV) to successfully remove calcified deposits.

We have recently tried unsuccessfully to use PPV to treat an 86 year old patient with calcification of a silicone IOL in the presence of asteroid hyalosis. We chose to avoid IOL exchange due to a history of Fuchs endothelial dystrophy and glaucoma in the left eye, and a failed corneal graft in a rubeotic eye on the right. Our patient did not have an intact posterior capsule having been treated with Nd:YAG capsulotomy 2 years previously, before the calcification occurred. A 25 gauge pars plana vitrectomy was performed after attempting to remove the deposits unsuccessfully from the posterior surface of the IOL with Nd:YAG laser. It was felt that PPV would be less likely to cause corneal decompensation than IOL exchange. In contrast to the experience of Mehta et $\mathrm{al}^{1}$ we found that the vitrector was unable to effectively remove many of the calcified deposits even with high vacuum. Instead the use of microforceps and a silicone tipped flute were required to 'polish' the IOL deposits (see Supplementary Video). Although we were able to remove a significant amount of the calcification in this way, the results were ultimately disappointing due to smearing of the deposits which were found to be 'putty-like' in consistency. Although there was some improvement in the clarity of the IOL on retroillumination, the patient reported very limited improvement in vision (6/18 preoperatively to 6/12 immediately after surgery), and on transillumination the posterior surface was significantly smudged (Figure 1).

Mehta et al reported that initially their patient underwent an unsuccessful Nd:YAG capsulotomy, however it was not made clear whether the posterior capsule remained intact. ${ }^{1}$ It has previously been suggested that direct contact of the IOL with the vitreous cavity caused by Nd:YAG capsulotomy accelerates the deposition of calcification on silicone IOLs, ${ }^{2}$ and other authors of larger case series of this condition have reported it to be mostly found after initial Nd:YAG capsulotomy, ${ }^{3,4}$ although reports of dystrophic calcification in the presence of an intact capsule do exist. ${ }^{5}$ Given our experience, we are unclear whether the photo presented demonstrates typical fibrous capsular opacity, or calcification of the posterior capsule rather than a true case of dystrophic calcification of the IOL optic. We believe this is an important distinction to make since we feel that vitrectomy is only likely to be successful if the posterior capsule is intact.
Eye Uninsbury

Cosham, Portsmouth, Hants,

PO6 3LY, UK

Tel +442392286000

Fax +441962 7I2I 45

Email paul.rainsbury@nhs.net 


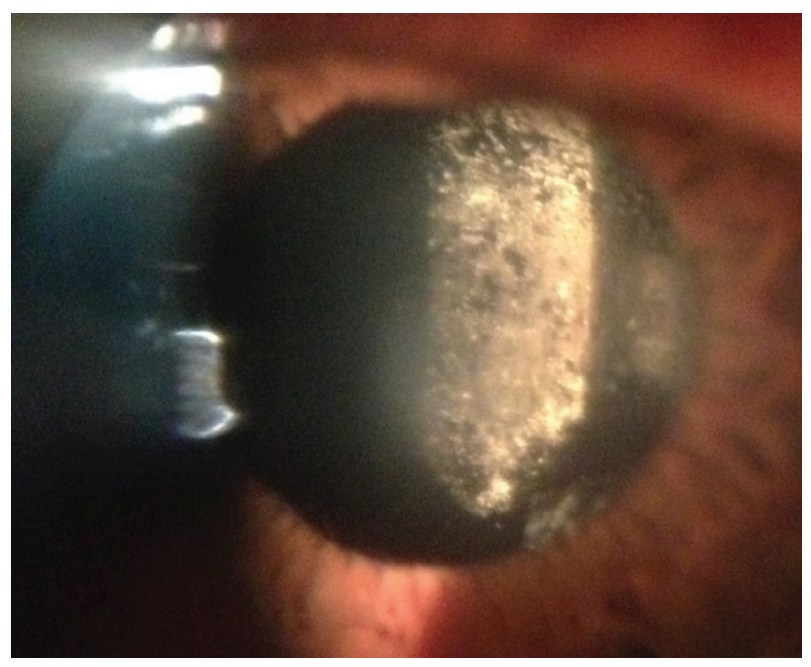

Figure I Smudging of posterior surface of IOL on transillumination postoperatively. Abbreviation: IOL, intraocular lens.

A similar case of this condition has been published recently by Ullman and Gupta. ${ }^{5}$ They also used vitrectomy to treat dystrophic calcification, but found it to be ineffective at removing established calcification on the posterior IOL surface on more than one occasion. They suggested using prophylactic PPV to treat dystrophic calcification at an early stage before symptoms become established.

We believe that vitrectomy and surgical capsulectomy should be considered as an alternative to Nd:YAG capsulotomy where IOL calcification is not yet established. It is likely that opening a significantly calcified posterior capsule by Nd:YAG capsulotomy in the presence of asteroid hyalosis will lead to significant future IOL dystrophic calcification. In established calcification of a silicone IOL we feel that vitrectomy is of limited value and IOL exchange should remain the standard treatment.

\section{Disclosure}

Some of this content was presented as a poster at the European Society of Cataract and Refractive Surgeons, London September 14th 2014. The authors declare no financial or proprietary conflict of interest in this work.

\section{References}

1. Mehta N, Goldberg RA, Shah CP. Treatment of dystrophic calcification on a silicone intraocular lens with pars plana vitrectomy. Clin Ophthalmol. 2014;8:1291-1293.

2. Werner L, Kollarits CR, Mamalis N, Olson RJ. Surface calcification of a 3-piece silicone intraocular lens in a patient with asteroid hyalosis: a clinicopathologic case report. Ophthalmology. 2005;112(3):447-452.

3. Stringham J, Werner L, Monson B, Theodosis R, Mamalis N. Calcification of different designs of silicone intraocular lenses in eyes with asteroid hyalosis. Ophthalmology. 2010;117(8):1486-1492.

4. Mamalis N, Brubaker J, Davis D, Espandar L, Werner L. Complications of foldable intraocular lenses requiring explantation or secondary intervention - 2007 survey update. J Cataract Refract Surg. 2008;34(9): $1584-1591$.

5. Ullman DI, Gupta S. Pars plana vitrectomy for dystrophic calcification of a silicone intraocular lens in association with asteroid hyalosis. J Cat Refract Surg. 2014;7:1228-1231. 


\section{Authors' response}

Nitish Mehta'

Roger A Goldberg ${ }^{2}$

Chirag P Shah ${ }^{2}$

'University of Massachusetts Medical School, Worcester, MA, USA; ${ }^{2}$ Department of Retina, Ophthalmic Consultants of Boston, Boston, Massachusetts, USA

Correspondence: Nitish Mehta

UCLA-Harbor Medical Center, 1000 W Carson St,

Torrance, CA 90502, USA

Email nmehta252@gmail.com

We appreciate Drs Rainsbury and Lochhead sharing their experience and insight into the treatment of dystrophic calcification of silicone intraocular lenses (IOL). As they point out, it intuitively makes sense that the presence or absence of a posterior capsule changes the natural history and management options of this pathologic calcification.

In our case, ${ }^{1}$ because of the poor visual potential in the fellow eye from retinal scarring and atrophy secondary to agerelated macular degeneration, we were reluctant to proceed with IOL exchange, though would have if necessary. The patient had already received two prior unsuccessful attempts with the Nd:YAG laser to remove the dystrophic material. During the vitrectomy, no clean surgical plane developed, and a modest degree of mechanical rubbing of the vitrectomy port against the lens optic using a high vacuum with a low cut rate was required to clear the central axis. The material appeared to be adherent directly to the posterior surface of the lens optic, and not to any residual posterior capsule, suggesting the posterior capsule was absent centrally. Had the posterior capsule been present, we suspect it would have been easier to remove the dystrophic material.

In the setting of monocular patients (as in our case) or those with compromised capsular support (as in the case described by Drs Rainsbury and Lochhead), we believe it is reasonable to attempt vitrectomy prior to IOL exchange in these cases of dystrophic calcification. Though vitrectomy might not be successful in every case, removing the vitreous alone may make subsequent IOL exchange safer, and prevent recurrence of dystrophic calcification.

\section{Disclosure}

The authors report no conflicts of interest in this correspondence.

\section{Reference}

1. Mehta N, Goldberg RA, Shah CP. Treatment of dystrophic calcification on a silicone intraocular lens with pars plana vitrectomy. Clin Ophthalmol. 2014;8:1291-1293.
Clinical Ophthalmology

\section{Publish your work in this journal}

Clinical Ophthalmology is an international, peer-reviewed journal covering all subspecialties within ophthalmology. Key topics include: Optometry; Visual science; Pharmacology and drug therapy in eye diseases; Basic Sciences; Primary and Secondary eye care; Patien Safety and Quality of Care Improvements. This journal is indexed on

\section{Dovepress}

PubMed Central and CAS, and is the official journal of The Society of Clinical Ophthalmology (SCO). The manuscript management system is completely online and includes a very quick and fair peer-review system, which is all easy to use. Visit http://www.dovepress.com/ testimonials.php to read real quotes from published authors. 